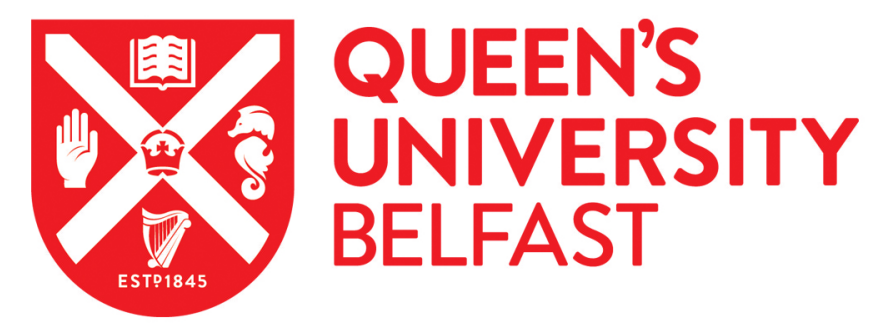

\title{
Antimicrobial 3D printed objects in the fight against pandemics
}

Mathew, E., Gilmore, B. F., Larrañeta, E., \& Lamprou, D. A. (2021). Antimicrobial 3D printed objects in the fight against pandemics. 3D Printing and Additive Manufacturing, 8(1), 79-86. https://doi.org/10.1089/3dp.2020.0267

\section{Published in:}

3D Printing and Additive Manufacturing

\section{Document Version:}

Peer reviewed version

Queen's University Belfast - Research Portal:

Link to publication record in Queen's University Belfast Research Portal

\section{Publisher rights}

(C) Mary Ann Liebert Inc

This work is made available online in accordance with the publisher's policies. Please refer to any applicable terms of use of the publisher.

\section{General rights}

Copyright for the publications made accessible via the Queen's University Belfast Research Portal is retained by the author(s) and / or other copyright owners and it is a condition of accessing these publications that users recognise and abide by the legal requirements associated with these rights.

Take down policy

The Research Portal is Queen's institutional repository that provides access to Queen's research output. Every effort has been made to ensure that content in the Research Portal does not infringe any person's rights, or applicable UK laws. If you discover content in the Research Portal that you believe breaches copyright or violates any law, please contact openaccess@qub.ac.uk. 


\title{
Antimicrobial 3D printed objects in the fight against pandemics
}

\author{
Essyrose Mathew ${ }^{1}$, Brendan F. Gilmore ${ }^{1}$, Eneko Larrañeta ${ }^{1}$, Dimitrios A. Lamprou ${ }^{1 *}$ \\ ${ }^{1}$ School of Pharmacy, Queen's University Belfast, 97 Lisburn Road, Medical Biology Centre, \\ Belfast BT9 7BL, UK. \\ * For correspondence: email: d.lamprou@qub.ac.uk, tel.: +44 (0)28 90972617.
}

\begin{abstract}
The uncharted nature of the Covid-19 pandemic has caused uncertainty globally, resulting in many healthcare professionals and key-workers being left with supply shortages in medical consumables and Personal Protective Equipment (PPE), exacerbated by supply line issues and in some cases delays resulting from governmental policies. 3D printing (3DP) has played an important role in providing essential items to hospitals and the wider communities, such as visors, facemasks and ventilator components. This short-review manuscript covers the potential of antimicrobial materials in the manufacturing of 3DP essential products, as an approach for added protection against pandemics.
\end{abstract}

Keywords: 3D-printing, additive manufacturing, antimicrobial activity, COVID-19, medical devices, pandemic.

\section{Introduction: COVID-19 \& Additive Manufacturing}

Coronaviruses are a large group of ribonucleic acid (RNA) viruses that cause acute respiratory infections in humans and animals. It is estimated that about one-third of upper respiratory tract infections in humans can be caused by coronaviruses with most people becoming infected with coronaviruses at least once in their life, with mild to moderate symptoms of a common cold. In January 2020, the Chinese health authorities announced that a new corona strain (SARS-CoV-2 or COVID-19, as it is commonly known) had been identified and spread in the city of Wuhan in Hubei Province (China's $7^{\text {th }}$ largest city). ${ }^{1}$ Shortly afterwards, the World Health Organization (WHO) declared COVID-19 as a pandemic, an epidemic of a contagious disease that spreads rapidly and threatens the entire population. Fig. 1 provides a map with the impacted places and percentage per country ${ }^{2}$. As of December 2020, over 65.6M people have been infected by COVID $-19,{ }^{3}$ which spreads with droplets from coughing or sneezing and symptoms may appear between 2-14 days with potential asymptomatic transmission. ${ }^{4}$

The world wasn't prepared for a global pandemic, despite many countries having pandemic preparedness plans and national pandemic strategies, which caused many issues in the supply of Personal Protective Equipment (PPE; e.g. goggles and visors) and Medical Devices (e.g. valves), among other essential healthcare items, thus exposing many healthcare and frontline/essential workers to additional risk of contracting the disease and without the appropriate consumables in the middle of this situation. The local communities, from large to small companies to individuals (e.g. craft workers, designers, and students), came together to 
assist by manufacturing different healthcare items with any resources that were available in their premises. Additive Manufacturing (AM) or 3D printing (3DP) techniques, have emerged as the technologies that have be rapidly and effectively employed during the pandemic for the manufacture of PPE and other antimicrobial materials, with numerous examples of 3DP items attracting significant press attention internationally, including face masks, face shields, nasopharyngeal swabs and door openers. ${ }^{5}, 6$ 3D offers immediate solutions where rapid response is required for restocking PPE or for special medical components (e.g. respirators) that are in short supply or vulnerable to supply-line interruption.

The rapid spread of COVID-19 around the world underscores the need for improved solutions and responses to fight pandemics and infectious diseases generally. 3DP for the manufacture of bespoke antimicrobial materials has the potential to play a vast role in pandemic response via the scalable manufacture of key components for prevention or protection. Antibacterial substances, support in preventing the development of bacteria, while antimicrobials support in preventing the spread and action of bacteria and (some) viruses. ${ }^{7,8}$ Thus, this article will cover the importance of 3DP in the fight against a pandemic, with the incorporation of antimicrobial filaments as a printing material for the manufacturing of PPE or medical consumables that will provide protection to the end user, and at the same time the additive effect of antimicrobial activity (e.g. antiviral, antifungal).

\section{3D-Printed Objects \& Antimicrobial Activity}

\subsection{D-Printing Processes in the biomedical field}

AM technologies are based on layer-by-layer manufacturing of digital data and are very attractive methods in the biomedical field as it can provide cost-effective bespoke items. AM provides the possibility to obtain PPE and other items relatively quickly and with the option of using a wide range of materials (e.g. composites, metals, polymers) with/without the combination of antimicrobial agents. Antimicrobial impregnated 3DP objects offer the benefits of increased surface area for drug distribution, consecutive layers of antimicrobial agent produced by layer-by-layer printing and the ability to fabricate personalised constructs on demand, according to patient anatomies.

According to the American Society for Testing and Materials (ASTM), AM processes are divided into seven categories: vat photo-polymerisation (e.g. Stereolithography), material jetting (e.g. Polyjet technology, Multi-Jet Printing), binding jetting (e.g. Colour Jet Printing, Digital Part Materialisation), material extrusion (e.g. fused deposition modelling), powder bed fusion (e.g. Electron beam melting, selective laser sintering), sheet lamination (e.g. Selective Deposition Lamination, Ultrasonic AM), and directed energy deposition (e.g. 3D laser cladding). One of the most commonly used 3DP technology is the Fused Deposition Modelling (FDM) printing, which is a versatile method of 3DP allowing a wide range of polymers to be used, and there are also no post printing steps making this method a solvent free printing process. FDM also allows antimicrobial constructs to be created easily by creating antimicrobial filaments using hot-melt extrusion (HME), in which polymer pellets can be combined with antimicrobial molecules or nanoparticles (NPs) in order to create 
antimicrobial-loaded filaments. ${ }^{9,}{ }^{10}$ Stereolithography (SLA) is another common method of $3 \mathrm{DP}$, in which $3 \mathrm{D}$ objects created by the photo-polymerisation of photopolymeric resins. ${ }^{11}$ SLA offers the advantage of having superior accuracy and resolution capabilities in comparison to other 3DP techniques, making it ideal for complex constructs and smaller products. Resins can be created with the addition of antimicrobial agents in order to create products with antimicrobial properties. ${ }^{12}$ Selective Laser Sintering (SLS) is also another common method of 3DP, based on the selective scanning and melting of powder polymer blends in consecutive cross sections according to a digital design. ${ }^{13}$ The areas of loose powder that are not scanned during a print act as supports for any overhanging areas of the print allowing complex geometries to be created with less waste of materials in the generation of supports. ${ }^{14}$ Both SLA and SLS, require post print processing steps that creates the need for additional materials and equipment, which can be a disadvantage during a pandemic environment as products needed to be created rapidly, within a short period of time. Moreover, potential toxicity issues in SLA printed parts need also to be considered, as can be caused by leaching of photoinitiator residues, which are prominently cytotoxic, and in some other cases due to incomplete printing or post-curing items.

In order to create antimicrobial 3DP products, the selection of the appropriate materials is crucial, as the antimicrobial activity can come from the materials itself or by post printing processes such as coating of the devices using dip-coating process or electrospinning (melt or solution) methods.

\subsection{Antimicrobial Materials for 3D printing: Manufacturing \& Mechanism of Action}

During WWI, doctors often used colloidal silver (Ag) to fight infections, however, Ag has been used for over 6,000 years according to historians for the treatment or prevention of infections. Silver in metallic, ionic and nanoparticulate form, has been used for disinfection and coatings on medical devices due to the broad-spectrum antimicrobial properties. Ag is currently being used in a variety of items, such as deodorants, bandages, and exercise equipment, as a biocide. In medicine, Silver nanoparticles (Ag-NPs) have been used to coat medical devices, dressings and as nanogels in cosmetics and lotions. ${ }^{15}$ The antimicrobial properties of the Ag NPs are dependent on the size, shape and surface charge of the Ag NPs. Ag-NPs have antiviral properties, with its mechanism of action having been studied against multiple enveloped proteins. ${ }^{16}$ AgNPs have also been shown to inhibit influenza virus as nanosilver may interfere with the fusion of the viral membrane, inhibiting viral penetration into the host cell. ${ }^{17}$ Tremiliosi et al., developed an Ag-NPs based antimicrobial polycotton that could potentially prevent the transmission and spread of Covid-19 virus. ${ }^{15}$ Tremiliosi et al., showed that these fabrics could be functionalised to have antiviral properties as well as antibacterial and antifungal properties. These antiviral fabrics could therefore be used to create protective garments for hospital staff and in the creation of face masks. ${ }^{15}$ When $\mathrm{Ag}$ is used, it is important to consider whether an increased exposure to Ag can lead to resistance among bacteria. Some side effects associated with the use of Ag NPs include local skin irritation such as contact dermatitis, hepatic and renal toxicities. ${ }^{18}$ Maroti et al., studied the effect of the high printing temperatures on FDM printing on PLA filaments combined with Ag NPs. The thermal analysis results showed that these composites were suitable for FDM 
printing; the PLA-Ag composites had improved thermal parameters in comparison to empty PLA. Bacterial studies showed that once the PLA-Ag 3D printed discs were removed from the bacterial milieu, no bacterial colonies had formed where the discs were placed, moreover, after removal no new bacterial colonies formed in the areas were the discs had been for weeks. ${ }^{19}$

In recent years, there has been significant interest in the application of copper $\left(\mathrm{Cu}^{2+}\right)$ across a broad range of applications, with the main current applications covering disinfection of water, as a preservative in liquid cooling systems, antifouling products and as antimicrobial surfaces in a healthcare setting. ${ }^{20} \mathrm{Cu}$ has also been used in cosmetic products (e.g. skin and hair) and have shown antioxidant and anti-inflammatory effects. Moreover, $\mathrm{Cu}$ has been used as a gel in hospitals and doctors' offices to heal and care for wounds as it kills bacteria, viruses and fungi. $\mathrm{Cu}$ antibacterial activity is thought to come from the ions released causing oxidative stress. ${ }^{21}$ After degrading the membrane, the released $\mathrm{Cu}^{2+}$ ions can penetrate into the cells. A summary of the mechanism of action of metal ions against viruses ${ }^{22}$ is shown in Fig.2. Cu has greater cytotoxicity in comparison to $\mathrm{Ag}$, however, has lower cost and elemental copper is in greater abundance in nature than silver. ${ }^{23} \mathrm{Cu}$ filaments for FDM printing currently exist on the market and can be used in the printing process of PPE and other medical equipment that may be required in a pandemic.

Plastics and polymers that can be used for the manufacturing of the antimicrobial filaments include Acrylonitrile butadiene styrene (ABS), Polycaprolactone (PCL), Polypropylene (PP), Polystyrene (PS), Polyvinyl chloride (PVC), Polylactic acid (PLA), and Thermoplastic polyurethane (TPU), among others. These polymers are commonly used as they can withstand the printing temperatures of 3DP as well as the temperatures of HME. Table 1 summarises the polymeric material properties along with their advantages and disadvantages. PLA has been the most commonly used polymer during the pandemic in 3DP, and is an ideal material for 3DP as it is renewable, low cost and compatible with most FDM 3D printers. ${ }^{24}$ These polymers can be combined with antimicrobial additives by the process of HME, which uses heat and pressure to melt polymer pellets along with additives to created uniform filaments for FDM printing. HME allows a wide range of antimicrobial additives to be used for 3DP, such as $\mathrm{Ag} / \mathrm{Cu}$ NPs or antimicrobial drugs. ${ }^{9}$ As already been stated, commercially available $\mathrm{Cu}$ filaments exist; however, readymade $\mathrm{Cu}$ filament is more expensive and therefore would increase cost of production.

Cellulose is a naturally occurring polymer that has been used in the creation of antimicrobial materials. Cellulose is cheap, biodegradable and renewable and is a favoured material for AM research and could aid the production of fast and low-cost devices required during a pandemic. $^{25}$ Although cellulose itself does not present any fundamental antimicrobial properties, it is a highly functional and biocompatible material and can be used as a nanocomposite in combination with antimicrobial agents for antimicrobial applications. ${ }^{26} \mathrm{~A}$ recent study on 3D printed composites using cellulose acetate (CA) showed that the 3D printed constructs had comparable mechanical properties to other thermoplastic materials such as ABS, PLA and nylon. Pattison et al., used known antimicrobial agents', toluidine and 
rose Bengal, combined with the $\mathrm{CA}$ to $3 \mathrm{D}$ print disks and exposed them to fluorescent lamp. After bacterial studies on $E$. coli, results showed that dyed CA enabled a reduction in bacterial count after exposure to fluorescent lamp. These light sources are commonly used in laboratories and hospitals which could allow for easy sterilised medical equipment. ${ }^{27}$ Ahmed et al., combined CA, PLA and copper oxide nanoparticles using electrospinning technique to create an antimicrobial and antiviral face mask. ${ }^{28}$ There are no studies using cellulose materials and AM technique for the fight against Covid-19, however, the studies above show that these materials could aid in lowering the viral load, allowing control of the spread of the virus and have the potential to be used in 3DP.

SLA resins have been used with the addition of polymer monomers containing positively charged quaternary ammonium groups to develop 3D printable antimicrobial resin. These resins have the ability to kill bacteria on contact. ${ }^{29} 3 \mathrm{D}$ printed antimicrobial hydrogels were also created using SLA with the ability to swell and shrink according to environmental $\mathrm{pH}$. The hydrogels presented excellent antimicrobial properties against $S$. aureus bacteria. A recent study by Makvandi et al., created dental bites with antimicrobial properties using SLA, in which a hydroxyapatite (HAP) resin was modified using methacrylate and quaternary ammonium compound, this solution was then added in different concentrations as a filler to custom-made SLA resin. The dental bites were successfully printed with dose-dependent reduction in bacterial and fungal growth and also showed an even distribution of HAP in the printed construct. $^{30}$

\subsection{Antimicrobial 3D-Printed Personal Protective Equipment (PPE) \& Medical Consumables}

Surface contamination has been found to play a significant role in the spread of COVID-19. Despite appropriate usage of PPE, healthcare workers were found to be contracting the virus, mainly due to air, environmental and PPE contamination. ${ }^{31}$ Therefore, antimicrobial materials used for 3DP would create an added level of protection to PPE and medical equipment. Common items that have been made using 3DP during the pandemic includes face-shields, N95 respirators, and oxygen valves, among others (Fig. 3).

Face shields are a popular piece of PPE that has been created using the AM technique throughout the pandemic. The use of antimicrobial materials for printing face-shields, for example, would not provide any major advantages as only the forehead part of the shield is made by 3DP mainly using PLA. ${ }^{32}$ Antimicrobial materials could be a valuable advantage in the printing of N95 respirators, as these surround the nose and mouth, two key areas through which viruses can enter the body. Antimicrobial filaments created using the HME process in combination with antimicrobial drugs or $\mathrm{Ag}$ or $\mathrm{Cu}$ NPs could be used to print these respirators. The antimicrobial properties of the respirators would therefore reduce viral adhesion and kill viruses on contact, lowering the risk of contamination to the user. Copper3D have developed a nanohack facemask using an innovative nanocomposite composed of PLA and a nano-copper additive. This composite can eliminate $99.9 \%$ of fungi, viruses, bacteria and a wide range of microorganisms. Zuniga et al., recently created a 3D antibacterial prostheses using PLACTIVE ${ }^{\mathrm{TM}}$ that contains copper nanoparticles, with finger prostheses successfully created using 3DP and an up to $99.99 \%$ effectiveness against 
S.aureus and E.coli. ${ }^{33}$ Due to the antiviral properties of the PLACTIVETM material, the face mask has been marketed for use during the pandemic, it could also be used to 3D print other essential PPE and medical equipment.

Ishack et al., proposed a 3D printed mask prototype in which multiple methods of 3DP (FDM, SLS, DMLS) could be used to create a novel N95 mask with multiple layers of materials such as an antimicrobial layer and odour reducing layer. ${ }^{34}$ This type of mask could provide many advantages, however, the need for multiple 3D printers and change of materials would increase the time of manufacture and cost significantly, also would complicate the process as it would be challenging to produce large quantities, especially during pandemics where medical supplies are required on demand and in a short period of time. Ishack et al., proposed creating tailored seal designs for the N95 respirators, which would result in improved comfort and fit in the end user. N95 respirators are $>95 \%$ efficient in filtering 0.3 $\mu \mathrm{m}$ particles that are airborne, these respirators can also be created customised to the user to create a better seal. Creating customised masks would require time to scan each individual face structure and creates a custom design. This would not be practical during a pandemic with supply shortages as it would require times and extra professionals to scan individual face structures and create designs accordingly. However, for medical professionals, this would be advantageous to have for future outbreaks, as it would provide greater comfort as medical professionals are required to wear masks for long periods throughout the day. High Efficiency Particulate Air Filter (HEPA) mask designs are available on Thingiverse (a website sharing 3DP designs) for users to download and use freely. As with all masks, it is important that appropriate testing of the seals and materials are completed. ${ }^{35}$ When creating 3DP masks, especially at a smaller scale, new users may not have sufficient knowledge and experience on the testing of seals and materials so there could be variations in quality in comparison to conventional masks.

Disposable ventilator valves can also be created using 3DP. Venturi valves are patented, however, under emergency situations such as the COVID-19 pandemic, intellectual property rights and copyright may be wavered in the appropriate clinical setting. ${ }^{35}$ These valves are used to deliver oxygen for patients with acute respiratory distress, which can occur in patients that have contracted corona virus. These valves have been created using the SLS technique by Issinova Technology Company in Milan and antimicrobial drug powders could be potentially combined with the material used in order to create antimicrobial valves. Shuai et al., have used the SLS method of 3DP to create antibacterial scaffolds using nano titanium dioxide (nTiO2) with polyetheretherketone/polyglycolicacid (PEEK/PGA). The resulting scaffolds possessed significant antibacterial capability against $S$. aureus and E. coli and the tensile strength and modulus of the scaffolds were also improved. ${ }^{36}$ Therefore, FDM and SLA methods could also be used to create these valves. Disposable valves would mean that sterilisation issues for reuse would not need to be considered.

High touch surfaces such as door handles, push plates, tables and switches are regarded as high-risk areas through which the virus can be spread. Even with rigorous cleaning protocols, there is a risk of contamination by the virus, especially in public areas where the frequency of 
users is higher. Direct Metal Laser Sintering (DMLS) can be used to coat surfaces with metal. The Australian company SPEE3D has developed new algorithms for their 3D printers to coat existing metal surfaces with antimicrobial $\mathrm{Cu}$. Results showed that $96 \%$ of the virus was killed after $2 \mathrm{~h}$ and $99.2 \%$ after $5 \mathrm{~h} .{ }^{37}$ This method could be employed in hospitals, schools and other areas to coat door handles, rails and touch plates. The need for a specialised 3D printer may not be ideal for immediate use in the current pandemic situation as other areas such as shortage of PPE and medical supply are of greater priority, including a focus for budgets and time. However, electroplating and coating of high touch surfaces with $\mathrm{Cu}$ could inhibit the spread of the virus for future outbreaks. A summary of antimicrobial materials mentioned and their potential uses in a pandemic situation are outlined in Table 2.

Many of the 3D printed PPE and medical equipment are designed to be reusable, therefore, it is up to the individual to appropriately sterilise the equipment after use. This requires more investigation into the maintenance of antimicrobial properties of the PPE after sterilisation. ${ }^{35}$ Due to the reusable nature of the 3DP masks, high-level disinfection techniques would need to be employed after each use. These disinfectants can contain concentrated alcohol or quaternary ammonium compounds; therefore, the correct selections will need to be made for disinfection according to compatibility with the printed material(s). PLA has been shown to undergo volume changes after sterilisation processes, using low-temperature hydrogen peroxide gas plasma technique. However, the morphological changes were minimal and the objects remained suitable for clinical use. This method of sterilisation is suitable for temperature sensitive materials as temperatures do not exceed $50{ }^{\circ} \mathrm{C}$ and the process can be carried out in low moisture environments. However, conventional sterilisation method of thermal steam sterilisation often requires a minimum temperature of $110{ }^{\circ} \mathrm{C}$, as well as high levels of humidity and dry heat sterilisation requires minimum temperature of $160{ }^{\circ} \mathrm{C} .{ }^{38}$ Therefore, in this study the sterilisation of PLA and polyethylene terephthalate glycol (PETG) printed objects were deformed by this method of sterilisation. ${ }^{39}$

\section{Conclusion}

The range of existing studies on the enhanced antimicrobial properties of 3D printed products with antimicrobial agents display the advantages antibacterial 3D printed products could play an important role in controlling the spread of a virus. However, more research is required into the effectiveness of the antimicrobial materials specifically on the SARS-CoV-2 strain of virus. FDM 3DP requires no post print processing methods such as washing and light curing that is required in SLA printing and requires less printing supports in comparison to SLA, decreasing the time for post processing. FDM printers are cheaper in comparison to SLA and SLS printers, allowing a greater accessibility by users that would like to help during a pandemic by providing a variety of 3D printed parts. However, the rough surfaces of FDM printed parts may not be ideal to keep out bacterial growth, which is the reason that many researchers are coating the final 3DP items. Coating of the 3DP device adds another step to the manufacturing process, resulting in a greater time of production and increased cost of manufacture. Higher drug load in antimicrobial filaments for FDM can also result in increased surface roughness of the print. ${ }^{40}$ It is important to consider the whole process, including these additional steps such as coating when calculating manufacturing costs and 
production time of the final product. Inaccuracies can occur in the final printed product according to the resolution of the $3 \mathrm{D}$ image loaded in the printer, as the resolutions of images can change according to the design software resulting in variations between prints. ${ }^{41}$ Many materials used for 3DP are not certified for safe use, therefore the safety of the products produced cannot be assured especially in the long term. The reliance on individual designers for the production of PPE can lead to production of equipment with little appreciation of the clinical needs of the product and on the ergonomic design. ${ }^{42}$ As there are no written set of standards when creating these products quality of the products, cannot be assured and a lot of variances can occur in the final product between the individuals producing the prints and between different methods of 3D printing. Overall, FDM based 3DP is convenient as is cheap, widely spread and the objects can be easily modified to generate prototypes, which makes it a suitable method for fast and on demand products that are required during a pandemic. Nowadays, many people have a 3DP in their premises and almost every hospital has 3DP, but not an injection moulder that is a convenient method for mass production.

\section{Expert Opinion}

Any claim towards a biocidal action in European Union (EU) must undergo the Biocide regulation and must be referred to an approved substance for that specific action. $\mathrm{Cu}$, for example, is an effective antimicrobial and has the potential to be used in medical device manufacturing; however, the benefits need to be balanced against the risks of long term inhalational and oral exposure. The U.S. Food and Drug Administration (FDA) and the Medicine and Healthcare products Regulatory Agency (MHRA) in UK, have both released guidance on 3DP of PPE and medical devices in a pandemic. ${ }^{43,}{ }^{44}$ In summary, it is important for manufactures to consider if there will be any increased risk in material properties and processing requirements in comparison to conventional production methods. Biological safety must also be evaluated to show that the 3D printed parts and any processing residues/degradation products are non-toxic to a high level of assurance. There is also guidance for new small-scale manufacturers of PPE during the pandemic, which small businesses, universities and academic institutions with 3D printers can follow in order to help the supply shortages of PPE. ${ }^{45}$

The COVID-19 pandemic highlights the potential for 3D printed products to be rapidly created and distributed in a safe and transparent manner in community and industry levels. ${ }^{46}$ Therefore, with greater focus on the area of 3DP with increased funding and robust regulatory guidance, this field could be fundamental for future outbreaks and for the rapid supply of medical devices or PPE.

\section{Author disclosure Statement}

No competing financial interests exist.

\section{Funding Information}

The authors thank Queen's University Belfast (QUB) in Belfast for the Ph.D. scholarship to EM. 


\section{References}

1. Rothan, H. A.; Byrareddy, S. N., The epidemiology and pathogenesis of coronavirus disease (COVID-19) outbreak. Journal of Autoimmunity 2020, 109, 102433.

2. WHO Coronavirus Disease (COVID-19) Dashboard. https://covid19. who.int/info (accessed 2 December 2020).

3. Worldometer COVID-19 Coronavirus Pandemic [Statistics]. https://www.worldometers.info/coronavirus/ (accessed 04/12/2020).

$4 . \quad$ Lai, C.-C.; Shih, T.-P.; Ko, W.-C., et al., Severe acute respiratory syndrome coronavirus 2 (SARS-CoV-2) and coronavirus disease-2019 (COVID-19): The epidemic and the challenges. International Journal of Antimicrobial Agents 2020, 55 (3), 105924.

5. Choong, Y. Y. C.; Tan, H. W.; Patel, D. C., et al., The global rise of 3D printing during the COVID-19 pandemic. Nature Reviews Materials 2020, 5 (9), 637-639.

6. Armani, A. M.; Hurt, D. E.; Hwang, D., et al., Low-tech solutions for the COVID-19 supply chain crisis. Nature Reviews Materials 2020, 5 (6), 403-406.

7. Cloutier, M.; Mantovani, D.; Rosei, F., Antibacterial Coatings: Challenges, Perspectives, and Opportunities. Trends in Biotechnology 2015, 33 (11), 637-652.

8. Quintavalla, S.; Vicini, L., Antimicrobial food packaging in meat industry. Meat Science 2002, 62 (3), 373-380.

9. Mathew, E.; Domínguez-Robles, J.; Stewart, S. A., et al., Fused Deposition Modeling as an Effective Tool for Anti-Infective Dialysis Catheter Fabrication. ACS Biomaterials Science \& Engineering 2019, 5 (11), 6300-6310.

10. Zuo, M.; Pan, N.; Liu, Q., et al., Three-dimensionally printed polylactic acid/cellulose acetate scaffolds with antimicrobial effect. RSC Advances 2020, 10 (5), 2952-2958.

11. Ambrosi, A.; Pumera, M., 3D-printing technologies for electrochemical applications. Chemical Society Reviews 2016, 45 (10), 2740-2755.

12. Sa, L.; Kaiwu, L.; Shenggui, C., et al., 3D printing dental composite resins with sustaining antibacterial ability. Journal of Materials Science 2019, 54 (4), 3309-3318.

13. Yuan, S.; Shen, F.; Chua, C. K., et al., Polymeric composites for powder-based additive manufacturing: Materials and applications. Progress in Polymer Science 2019, 91, 141-168.

14. Turner, R. D.; Wingham, J. R.; Paterson, T. E., et al., Use of silver-based additives for the development of antibacterial functionality in Laser Sintered polyamide 12 parts. Scientific Reports 2020, $10(1), 892$.

15. Tremiliosi, G. C.; Simoes, L. G. P.; Minozzi, D. T., et al., Ag nanoparticles-based antimicrobial polycotton fabrics to prevent the transmission and spread of SARS-CoV-2. bioRxiv 2020,

2020.06.26.152520.

16. Lara, H. H.; Garza-Treviño, E. N.; Ixtepan-Turrent, L., et al., Silver nanoparticles are broadspectrum bactericidal and virucidal compounds. Journal of Nanobiotechnology 2011, 9 (1), 30.

17. Mehrbod, P.; Motamed, N.; Tabatabaian, M., et al., In Vitro Antiviral Effect of "Nanosilver" on Influenza Virus. DARU Journal of Pharmaceutical Sciences 2009, 17.

18. Hadrup, N.; Sharma, A. K.; Loeschner, K., Toxicity of silver ions, metallic silver, and silver nanoparticle materials after in vivo dermal and mucosal surface exposure: A review. Regul Toxicol Pharmacol 2018, 98, 257-267.

19. Maróti, P.; Kocsis, B.; Ferencz, A., et al., Differential thermal analysis of the antibacterial effect of PLA-based materials planned for 3D printing. Journal of Thermal Analysis and Calorimetry 2020, 139 (1), 367-374.

20. Michels, H. T.; Keevil, C. W.; Salgado, C. D., et al., From laboratory research to a clinical trial: copper alloy surfaces kill bacteria and reduce hospital-acquired infections. HERD: Health Environments Research \& Design Journal 2015, 9 (1), 64-79.

21. Vincent, M.; Duval, R. E.; Hartemann, P., et al., Contact killing and antimicrobial properties of copper. Journal of Applied Microbiology 2018, 124 (5), 1032-1046. 
22. Pemmada, R.; Zhu, X.; Dash, M., et al., Science-Based Strategies of Antiviral Coatings with Viricidal Properties for the COVID-19 Like Pandemics. Materials 2020, 13 (18), 4041.

23. Godymchuk, A.; Frolov, G.; Gusev, A., et al., Antibacterial Properties of Copper Nanoparticle Dispersions: Influence of Synthesis Conditions and Physicochemical Characteristics. IOP Conference Series: Materials Science and Engineering 2015, 98, 012033.

24. Zuniga, J. M.; Cortes, A., The role of additive manufacturing and antimicrobial polymers in the COVID-19 pandemic. Expert Review of Medical Devices 2020, 17 (6), 477-481.

25. González-Henríquez, C. M.; Sarabia-Vallejos, M. A.; Rodríguez Hernandez, J., Antimicrobial Polymers for Additive Manufacturing. International Journal of Molecular Sciences 2019, 20 (5).

26. Forero-Doria, O.; Polo, E.; Marican, A., et al., Supramolecular hydrogels based on cellulose for sustained release of therapeutic substances with antimicrobial and wound healing properties. Carbohydrate Polymers 2020, 242, 116383.

27. Pattinson, S. W.; Hart, A. J., Additive manufacturing of cellulosic materials with robust mechanics and antimicrobial functionality. Advanced Materials Technologies 2017, 2 (4), 1600084.

28. Ahmed, M. K.; Afifi, M.; Uskoković, V., Protecting healthcare workers during COVID-19 pandemic with nanotechnology: A protocol for a new device from Egypt. Journal of Infection and Public Health 2020, 13 (9), 1243-1246.

29. Yue, J.; Zhao, P.; Gerasimov, J. Y., et al., 3D-Printable antimicrobial composite resins. Advanced functional materials 2015, 25 (43), 6756-6767.

30. Makvandi, P.; Esposito Corcione, C.; Paladini, F., et al., Antimicrobial modified hydroxyapatite composite dental bite by stereolithography. Polymers for Advanced Technologies 2018, 29 (1), 364-371.

31. Ong, S. W. X.; Tan, Y. K.; Chia, P. Y., et al., Air, surface environmental, and personal protective equipment contamination by severe acute respiratory syndrome coronavirus 2 (SARSCoV-2) from a symptomatic patient. Jama 2020, 323 (16), 1610-1612.

32. Larrañeta, E.; Dominguez-Robles, J.; Lamprou, D. A., Additive Manufacturing Can Assist in the Fight Against COVID-19 and Other Pandemics and Impact on the Global Supply Chain. 3D Printing and Additive Manufacturing 2020, 7 (3), 100-103.

33. Zuniga, J. M., 3D Printed Antibacterial Prostheses. Applied Sciences 2018, 8 (9), 1651.

34. Ishack, S.; Lipner, S. R., Applications of 3D Printing Technology to Address COVID-19 Related Supply Shortages. The American Journal of Medicine 2020.

35. Tino, R.; Moore, R.; Antoline, S., et al., COVID-19 and the role of 3D printing in medicine. 3D Printing in Medicine 2020, 6 (1), 11.

36. Shuai, C.; Shuai, C.; Feng, P., et al., Antibacterial Capability, Physicochemical Properties, and Biocompatibility of nTiO2 Incorporated Polymeric Scaffolds. Polymers 2018, 10 (3), 328.

37. Carlota, V. 3D printing copper on surfaces can kill COVID-19 virus.

https://www.3dnatives.com/en/copper-covid-19-250420204/\#! (accessed 29/07/2020).

38. Agency, E. M., Guideline on the sterilisation of the medicinal product, active substance, excipient and primary container. 2019.

39. Oth, O.; Dauchot, C.; Orellana, M., et al., How to Sterilize 3D Printed Objects for Surgical Use? An Evaluation of the Volumetric Deformation of 3D-Printed Genioplasty Guide in PLA and PETG after Sterilization by Low-Temperature Hydrogen Peroxide Gas Plasma. The Open Dentistry Journal 2019, 13 (1).

40. Water, J. J.; Bohr, A.; Boetker, J., et al., Three-dimensional printing of drug-eluting implants: preparation of an antimicrobial polylactide feedstock material. J Pharm Sci 2015, 104 (3), 1099-107.

41. Martelli, N.; Serrano, C.; van den Brink, H., et al., Advantages and disadvantages of 3dimensional printing in surgery: a systematic review. Surgery 2016, 159 (6), 1485-1500.

42. Shpichka, A.; Bikmulina, P.; Peshkova, M., et al., Engineering a Model to Study Viral Infections: Bioprinting, Microfluidics, and Organoids to Defeat Coronavirus Disease 2019 (COVID-19). 20202020,6 (4). 
43. Agency, M. a. H. P. R. 3D printing (additive manufacturing) of medical devices or component parts during the coronavirus (COVID-19) pandemic. https://www.gov.uk/guidance/3d-printingadditive-manufacturing-of-medical-devices-or-component-parts-during-the-coronavirus-covid-19pandemic (accessed 03/08/2020).

44. FDA 3D Printing of Medical Devices, Accessories, Components, and Parts During the COVID19 Pandemic. https://www.fda.gov/medical-devices/coronavirus-covid-19-and-medical-devices/3dprinting-medical-devices-accessories-components-and-parts-during-covid-19-pandemic (accessed 2020).

45. Standards, O. f. P. S. New Small-Scale Manufacturers of COVID-19 Personal Protective Equipment (PPE). https://www.gov.uk/guidance/opss-coronavirus-covid-19- guidance-for-businessand-local-authorities (accessed 29/07/2020).

46. Lamprou D.A. Emerging technologies for diagnostics and drug delivery in the fight against COVID19 and other pandemics. Expert Review of Medical Devices 2020, DOI:

10.1080/17434440.2020.1792287. 


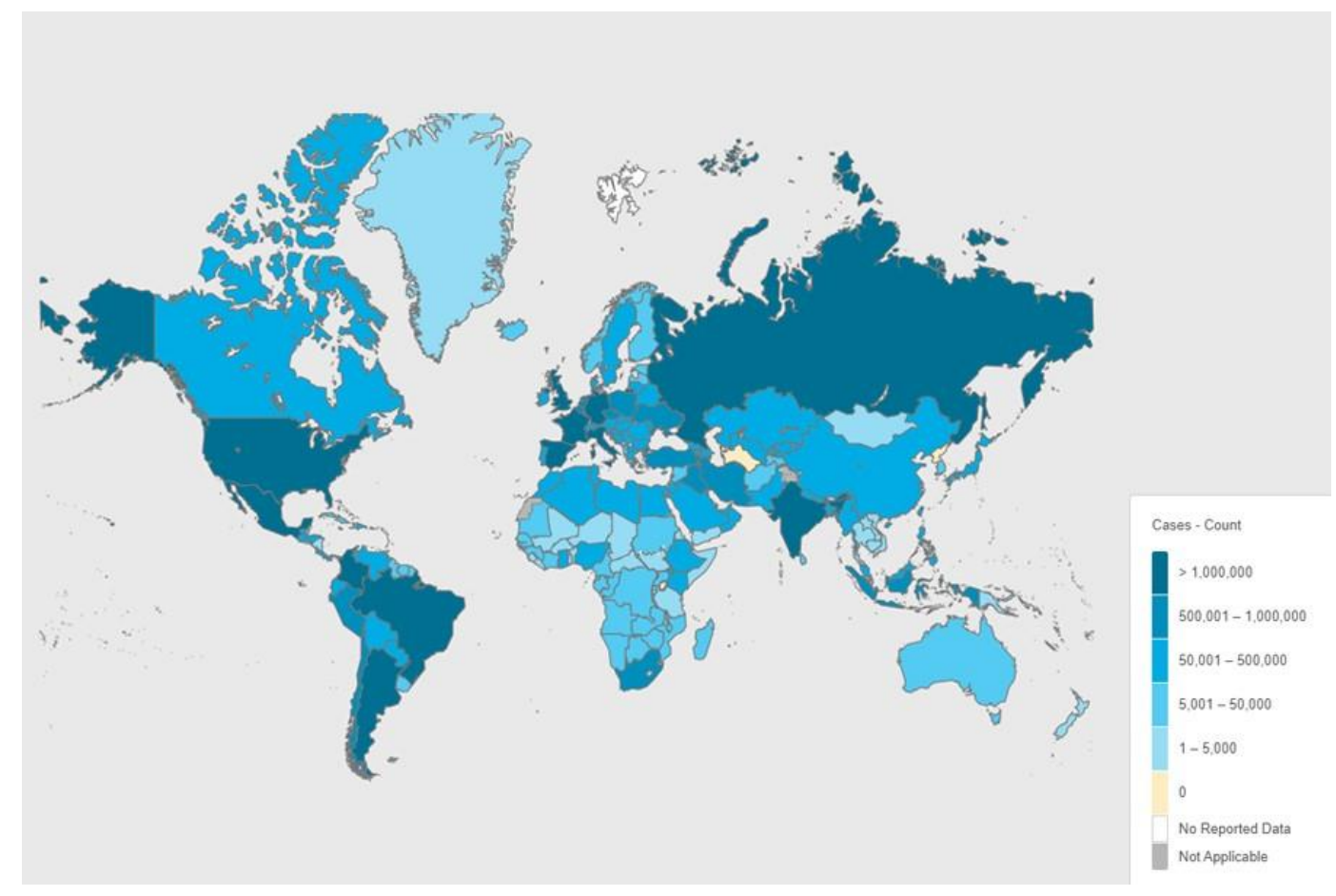

Fig. 1. Number of Corona Virus cases reported worldwide (reported as of 2nd Dec 2020)2. 


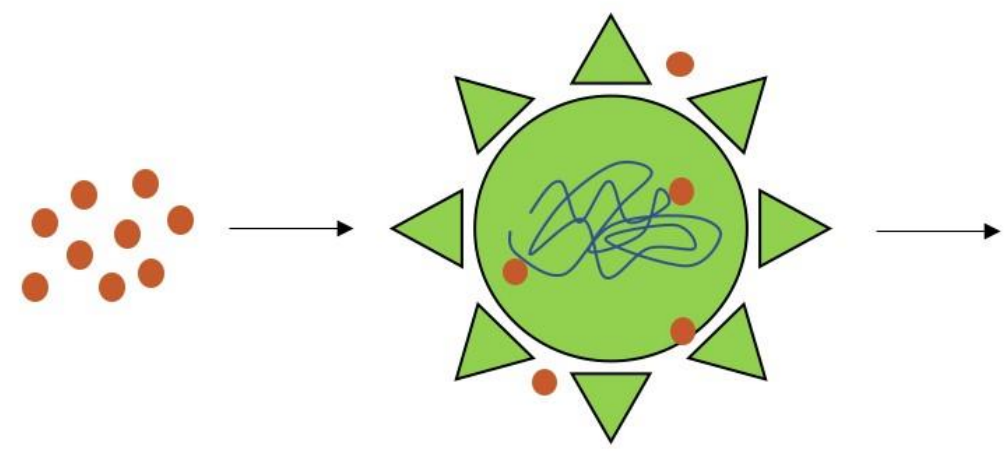

Metal ions e.g. copper and silver ions

Metal ions can destroy the protein shell of viral pathogen

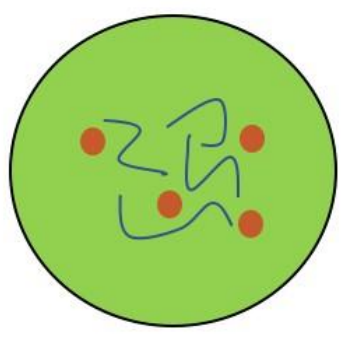

Metal ions can enter the viral pathogen and destroy RNA/DNA

Fig. 2. Mechanism of action of antiviral metallic ions ${ }^{22}$. 


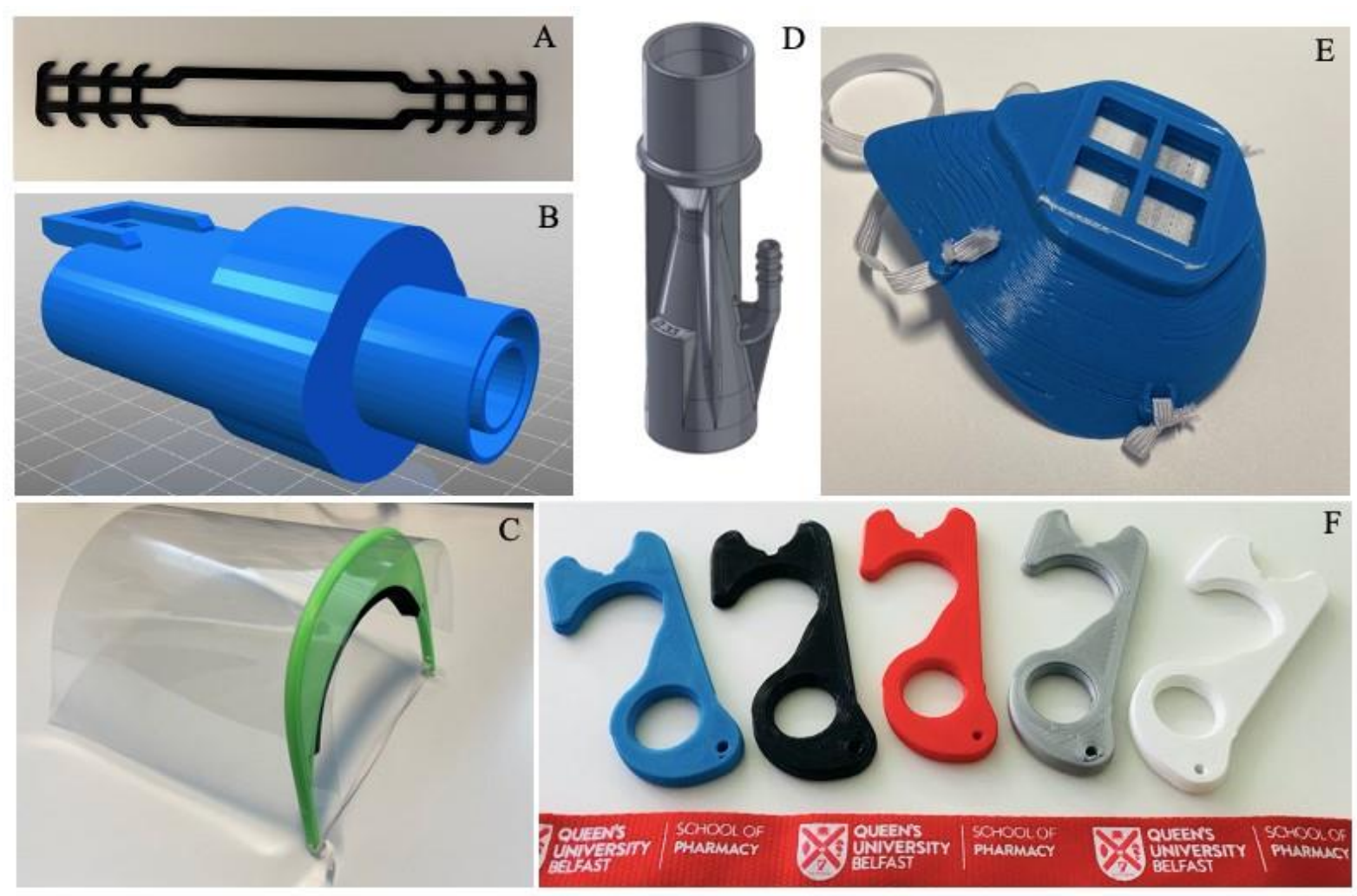

Fig. 3. Examples of 3D printed PPE and medical equipment: (a) mask adjuster, (b) scuba adaptor, (c) face-shield, (d) ventilator valve, (e) N95 respirator and (f) "no-touch" door opener. 
Table 1. Summary of polymeric materials used for FDM Printing.

\begin{tabular}{|c|c|c|c|}
\hline Material & Printing Temperature $/{ }^{\circ} \mathrm{C}$ & Advantages & Disadvantages \\
\hline BS & $230-260$ & Strong material, reusable, low cost & $\begin{array}{l}\text { Not biodegradable, prone to warping and } \\
\text { shrinkage post print, gives off toxic fumes }\end{array}$ \\
\hline PCL & $59-64$ & Flexible, low cost, good thermal stability & Low solidifying rate, low melt strength \\
\hline PLA & $190-230$ & $\begin{array}{l}\text { Biodegradable, renewable, high tensile } \\
\text { strength }\end{array}$ & $\begin{array}{l}\text { High cooling and solidification speed makes it } \\
\text { difficult to manipulate, prints can degrade over } \\
\text { time }\end{array}$ \\
\hline PP & $220-250$ & $\begin{array}{l}\text { impact resistant, heat resistant, chemically } \\
\text { stable }\end{array}$ & Prone to warping, poor bed adhesion, expensive \\
\hline PS & $230-245$ & $\begin{array}{l}\text { Low cost, lightweight, impact and water } \\
\text { resistant, rigid }\end{array}$ & High printing temperature, ventilation required \\
\hline PVC & $180-210$ & Chemical resistant, durable & $\begin{array}{l}\text { Can emit corrosive gas, requires specialist } \\
\text { printer/filament for safe use }\end{array}$ \\
\hline TPU & $190-220$ & Elastic, low shrinkage, strong & $\begin{array}{l}\text { Hygroscopic, more difficult to print due to } \\
\text { flexibility }\end{array}$ \\
\hline
\end{tabular}


Table 2. Antimicrobial agents and their potential use in AM, in the fight against pandemics.

\begin{tabular}{ccc}
\hline Antimicrobial Agent & AM Method & Potential Uses \\
\hline $\mathrm{Cu}$ & FDM, DMLS & $\begin{array}{c}\text { Door openers }{ }^{23} \text {, switches, } \\
\text { high touch surfaces }\end{array}$ \\
\hline $\mathrm{Ag}$ & FDM, DMLS & $\begin{array}{c}\text { Venturi valves, do or-openers, } \\
\text { respirators }\end{array}$ \\
Quaternary ammonium compounds & SLA & Venturi valves \\
\hline Antimicrobial drug powder & FDM, SLS & $\begin{array}{c}\text { Oxygen valves, face-shields, } \\
\text { face masks }\end{array}$ \\
\hline
\end{tabular}

